\title{
Health-Related Quality of Life and Associated Factors of Children with Transfusion-Dependent Thalassemia in Dubai, United Arab Emirates
}

\author{
Shaikha Alshamsi ${ }^{1}$, Samer Hamidi ${ }^{2} \&$ Hacer Ozgen Narci $^{3}$ \\ ${ }^{1}$ Ph.D. Student at Hamdan bin Mohammed Smart University, Dubai, UAE \\ ${ }^{2}$ School of Health and Environment Studies, Hamdan Bin Mohammed Smart University, Dubai, UAE \\ ${ }^{3}$ Department of Health Management, Istinye University, Istanbul, Turkey \\ Correspondence: Shaikha Alshamsi, School of Health and Environmental Studies, Hamdan bin Mohamed Smart \\ University, Dubai, UAE.
}

Received: April 16, 2021 Accepted: May 21, 2021 Online Published: May 25, 2021

doi:10.5539/gjhs.v13n7p18 URL: https://doi.org/10.5539/gjhs.v13n7p18

\begin{abstract}
Background: Patients with transfusion-dependent thalassemia require lifelong blood transfusions and iron chelation therapy. Iron overload associated with regular blood transfusion leads to a significant defect in the health-related quality of life (HRQoL) of patients with transfusion-dependent thalassemia. Quality of life has become a significant component of care, and it is therefore necessary to focus on the HRQoL of patients with transfusion-dependent thalassemia.
\end{abstract}

Objectives: To assess the HRQoL of children with transfusion-dependent thalassemia, identify the sociodemographic and clinical characteristics that affect the HRQoL, and identify the risk factors for poor HRQoL in children with transfusion-dependent thalassemia.

Study Design: A descriptive cross-sectional study was used to address the study's objectives.

Setting: A representative sample was recruited from the Dubai Thalassemia Center in the United Arab Emirates (UAE).

Participants: A total of 68 children with transfusion-dependent thalassemia aged 2-18 years.

Intervention: PedsQL 4.0 was applied to assess the HRQoL. The total HRQoL score was treated as the dependent variable in the study. Regression analysis was applied to study the effect of sociodemographic and clinical characteristics on HRQoL.

Results: This study included 68 children with transfusion-dependent thalassemia. Among them, $55.9 \%$ fell into the 13-18-year age group, and $42.6 \%$ were male. In addition, $57.4 \%$ were non-UAE nationals, and $44.1 \%$ of the children had less than 10,000 AED as monthly household income. The median (IQR) physical health summary score was 89.9 (15.6) and the psychosocial health summary score was 90.0 (10.3). Total PedsQL scores were significantly higher for younger children, those with a higher monthly household income, and those without complications. Older children were significantly correlated with lower total, physical, and psychosocial health summary PedsQL scores, whereas lower monthly household income was significantly correlated with lower total and psychosocial health summary PedsQL scores. Controlling for other variables, increasing age of patients was associated with worse total PedsQL scores.

Conclusions: Children with transfusion-dependent thalassemia and their families require long-term support for the prevention of physical and mental problems associated with this disease.

Keywords: Health-related quality of life, pediatric quality of life inventory (PedsQL), transfusion-dependent thalassemia, United Arab Emirates

\section{Introduction}

\subsection{The problem}

Transfusion-dependent thalassemia (TDT) has developed from one of the deadliest diseases to a chronic condition with prolonged life (Galanello \& Origa, 2010). The survival of TDT patients has improved dramatically over the last decades as reported by different large observational cohorts (Borgna-Pignatti Caterina, 2010; Cunningham et al., 2004; Dhanya et al., 2020), mainly as a result of the remarkable improvement in blood transfusion regimens, iron chelation therapy (ICT), intensive cure of infections, and advanced management of heart diseases (Dhirar et 
al., 2016; Vitrano et al., 2017). Quality of life has become a significant component of care (Gollo, Savioli, Balocco, et al., 2013). However, few published studies cover the health-related quality of life (HRQoL) among TDT patients, especially in children in the United Arab Emirates (UAE) (Hachim, Nuaimi, \& Baky, 2014; Mahmoud, 2015; Salama et al., 2014).

\subsection{Importance of the Problem}

Life-long regular blood transfusions are the mainstay for the management of TDT (Bayanzay \& Alzoebie, 2016). The quality of life is the main index for the thalassemia treatment's effectiveness (Emadi Dehaghi, Rasooli, \& Mohammadi Farsani, 2016). Measurement of HRQoL has been employed as an indicator for measuring the effectiveness of a specific treatment, regulatory policy, or success of a health program (Feeny et al., 2013). Moreover, evaluation of factors associated with the HRQoL is essential in developing clinical, counseling, social, and school support programs that could positively affect the treatment outcome (Mevada et al., 2016).

This study was proposed to assess the HRQoL associated with TDT in Dubai, UAE, and also to encourage clinical professionals and policymakers to use the HRQoL as an indicator to evaluate the improvement in the healthcare of patients with transfusion-dependent thalassemia. Therefore, this study aimed:

1) To evaluate the HRQoL in children with TDT using PedsQL 4.0.

2) To identify the sociodemographic and clinical characteristics that affect the HRQoL in children with TDT.

3) To identify the risk factors for poor HRQoL in Children with TDT.

\subsection{Relevant Literature}

The quality of life measurement is an important instrument to evaluate the impact of disease on a patient's well-being (Germain, Aballéa, \& Toumi, 2019). Several aspects are covered in PedsQL, including physical, psychological, and social functioning (Varni J. W., Seid, \& Kurtin, 2001). Patients with TDT suffer from clinical and psychological disorders such as frequent hospital visits and night subcutaneous infusions, poor self-image due to skeletal deformities and short stature, endocrine abnormalities, cardiovascular disorders, infections, and worries about the future (Telfer et al., 2005).

Many studies revealed that TDT children had the lowest ratings in school and emotional functioning and the highest ratings in physical and social functioning (El-Dakhakhny, 2011; Mevada et al., 2016; Thavorncharoensap et al., 2010). Children with TDT had significantly lower school functioning compared to healthy children (Mevada et al., 2016; Nashwan et al., 2018). Using deferoxamine was a predictor for lower school functioning (Thavorncharoensap et al., 2010), while the physical functioning of TDT patients was predicted by the patient's age (Shafie et al., 2020), severity of the disease (Hadi, Karami, \& Montazeri, 2009), history of thalassemia in the family, and low financial status (Ayoub et al., 2013).

HRQoL is influenced by different determinants, such as ICT, family history of thalassemia, and thalassemia complications (Gharaibeh \& Gharaibeh, 2011; Salama et al., 2014). Other studies revealed that age at onset of low hemoglobin, age at first blood transfusion, pre-transfusion hemoglobin level, and severity of the condition affect the patients' QoL (Thavorncharoensap et al., 2010).

Higher pretransfusion hemoglobin levels and low serum ferritin levels were independent predictors of better QoL scores (Elalfy et al., 2014; Mevada et al., 2016), while poor QoL was associated with the presence of complications, low economic level, female sex, hepatomegaly, high ferritin level (Clarke et al., 2010; Hakeem et al., 2018; Jameel \& Im, 2015; Sobota et al., 2011; Tuysuz \& Tayfun, 2017), increasing age, and the use of combined therapy of ICT, (Shafie et al., 2020). Furthermore, delays in diagnosis and introduction of ICT contributed to a negative effect on the total PedsQL score (Mevada et al., 2016).

These factors cover broad aspects ranging from physical, psychological, emotional, and social health to personal experiences, culture, and spiritual beliefs (Bullinger, 2002; Mueller, Plevak, \& Rummans, 2001). Therefore, the assessment of these factors may help in applying the appropriate interventions to deal with affected components. Many studies have been conducted to assess the HRQoL in TDT patients and concluded that knowledge of factors associated with the HRQoL among patients with TDT is essential in improving these patients' treatment outcomes (Dhirar et al., 2016; Thavorncharoensap et al., 2010).

\subsection{Research Questions}

The study addressed the following questions:

1) What impact does TDT have on children's HRQoL in Dubai, UAE?

2) What are the factors influencing the HRQoL among children with TDT in Dubai, UAE? 


\section{Method}

\subsection{Study Design and Setting}

A descriptive cross-sectional study was conducted at the Dubai Thalassemia Center, Dubai, UAE, between December 2019 and January 2020.

\subsection{Participant Characteristics}

Children with TDT aged between 2 and 18 years old at the Dubai Thalassemia Center were invited to participate in the study.

\subsection{Sampling Procedures}

The sample size was calculated based on the following formula (Watson, 2001),

$$
n=\left(P[1-P] /\left(A^{2} / Z^{2}\right)+P[1-P] / N\right) / R
$$

Where:

$n=$ sample size required

$\mathrm{N}=$ number of people in the population (80 children)

$\mathrm{P}=$ estimated variance in the population, as a decimal ( 0.5 for 50-50 variability)

$A=$ Precision desired, expressed as a decimal ( 0.05 for $5 \%)$

$\mathrm{Z}=$ Based on confidence interval: 1.96 for $95 \%$ confidence

$\mathrm{R}=$ Estimated response rate, as a decimal ( $97 \%$ according to pilot study)

According to the previous equation (1), and based on the $5 \%$ error margin, with a $95 \%$ confidence interval, a minimum of 68 children with TDT were required to conduct the study, considering that $5 \%$ of the sample would be excluded from the analysis because of possible non-response due to the respondents' health status. Surveys were distributed using a random sampling technique to 72 children. All children diagnosed with $\beta$-thalassemia major, $\beta$-thalassemia intermedia, $\beta$-thalassemia $/ \mathrm{Hb} \mathrm{E}$, and $\alpha$-thalassemia $(\mathrm{Hb} \mathrm{H}$ disease) and on a regular blood transfusion for at least one year were included in the study. Male and female patients and aged equal or more than two years were included. Patients diagnosed with other blood disorders such as sickle cell anemia, sickle cell/ $\beta$-thalassemia, diamond black fan anemia, Hamer Smith, and $\beta$-thalassemia intermedia on irregular blood transfusion were excluded from the study. Patients aged less than two years or those who started blood transfusion recently, patients with mental disorders or language difficulties, and patients who went under HSCT were excluded from the study.

\subsection{Data Collection}

HRQoL assessment was performed using two Pediatric Quality of Life Inventory (PedsQL) 4.0 Generic Core Scales- Arabic and English versions. The questionnaire has child self-reports and parent reports, and consists of four scales divided into twenty-three items assessing the level of physical and psychological functioning of children. Physical functioning (PF) consists of eight items, and psychosocial functioning is divided into three subscales: emotional functioning (EF), social functioning (SF), and schooling performance (SC), each consisting of five items. Items were scaled on a 5-point Likert scale from zero (Never) to four (Almost always), with corresponding scores of 100, 75, 50, 25, and 0. The Arabic and English versions of PedsQL 4.0 were considered to have satisfactory psychometric properties (Arabiat et al., 2011; Varni J. W. et al., 2001).

\subsection{Data Analysis}

Data analysis was performed using STATA C16. The normality of the distribution was assessed through the One-Sample Kolmogorov-Smirnov Test for all variables, which indicated that all continuous variables were non-normally distributed. Descriptive analysis was done using and median and interquartile range for skewed data.

For comparison of continuous variables that were non-normally distributed, the Mann-Whitney U test (for two groups) or Kruskal-Wallis H test (for multiple groups) was used. Wilcoxon signed ranks test was used to compare two related samples with non-normally distributed variables, and Spearman correlation was used to study the association between continuous non-normally distributed variables. A linear regression model was used to identify the factors of the HRQoL among TDT children. In contrast, logistic regression was used to study the risk factors for low HRQoL scores in TDT children. All inferential tests were two-sided and utilized a 95\% significance level. A p-value threshold of $<0.05$ was considered statistically significant.

\subsection{Ethical Consideration}

The study was approved by the Research Ethics Committee at Hamdan Bin Mohammed Smart University and 
Dubai Scientific Research Ethics Committee - Dubai Health Authority. The requisite permission from MAPI trust was received to use the Pediatric Quality of Life Inventory (PedsQL) Generic core 4.0 questionnaire for assessing the QOL in children with TDT. After explaining the study design and objectives, informed consent was obtained from the participants or guardians of children aged $<18$ years and ensuring the right to withdraw at any time during the study.

\section{Results}

\subsection{Demographic, Socioeconomic, and Clinical Characteristics of Children with TDT}

The study was conducted from December 2019 to January 2020. A total of 72 children were included in the study; 68 children agreed to participate in this study, with a response rate of $94.4 \%$, while four patients refused to participate.

Table 1. Demographic, socioeconomic, and clinical characteristics of children with TDT

\begin{tabular}{|c|c|c|}
\hline Characteristics & $\mathbf{N}$ & $\%$ \\
\hline \multicolumn{3}{|l|}{ Age (years) } \\
\hline $2-4$ & 7 & $10.3 \%$ \\
\hline $5-7$ & 9 & $13.3 \%$ \\
\hline $8-12$ & 14 & $20.6 \%$ \\
\hline $13-18$ & 38 & $55.9 \%$ \\
\hline \multicolumn{3}{|l|}{ Sex } \\
\hline Male & 29 & $42.6 \%$ \\
\hline Female & 39 & $57.4 \%$ \\
\hline \multicolumn{3}{|l|}{ Education level } \\
\hline Below school-age & 5 & $7.4 \%$ \\
\hline Pre-schooler & 8 & $11.8 \%$ \\
\hline Attending school & 55 & $80.9 \%$ \\
\hline \multicolumn{3}{|l|}{ Household monthly income (AED) } \\
\hline$<5000$ & 12 & $17.6 \%$ \\
\hline $5,000-9,999$ & 18 & $26.5 \%$ \\
\hline $10,000-19,999$ & 20 & $29.4 \%$ \\
\hline $20,000-29,999$ & 10 & $14.7 \%$ \\
\hline $30,000-39,999$ & 1 & $1.5 \%$ \\
\hline$\geq 40,000$ & 7 & $10.3 \%$ \\
\hline \multicolumn{3}{|l|}{ Nationality } \\
\hline UAE & 29 & $42.6 \%$ \\
\hline Non-UAE & 39 & $57.4 \%$ \\
\hline \multicolumn{3}{|l|}{ Disease type } \\
\hline$\beta$-thalassemia major (BTM) & 59 & $86.7 \%$ \\
\hline$\beta$-thalassemia intermedia (BTI) & 7 & $10.3 \%$ \\
\hline $\mathrm{HbE} / \beta$-thalassemia $(\mathrm{HbE} / \mathrm{BT})$ & 1 & $1.5 \%$ \\
\hline A-thalassemia intermedia $(\mathrm{HbH})$ & 1 & $1.5 \%$ \\
\hline \multicolumn{3}{|l|}{ Type of iron chelation therapy (ICT) } \\
\hline Deferasirox (DFX) & 56 & $82.4 \%$ \\
\hline Deferiprone (DFP) & 1 & $1.5 \%$ \\
\hline Deferoxamine (DFO) & 9 & $13.2 \%$ \\
\hline
\end{tabular}




\begin{tabular}{|c|c|c|}
\hline Combined therapy & 2 & $2.9 \%$ \\
\hline \multicolumn{3}{|l|}{ Ferritin level } \\
\hline$<2000 \mathrm{ng} / \mathrm{ml}$ & 25 & $36.8 \%$ \\
\hline$\geq 2000 \mathrm{ng} / \mathrm{ml}$ & 43 & $63.2 \%$ \\
\hline \multicolumn{3}{|l|}{ History of splenectomy } \\
\hline No & 67 & $98.5 \%$ \\
\hline Yes & 1 & $1.5 \%$ \\
\hline \multicolumn{3}{|l|}{ Complications no. } \\
\hline No complication & 39 & $57.4 \%$ \\
\hline One complication & 25 & $36.8 \%$ \\
\hline Two complications & 4 & $5.9 \%$ \\
\hline \multicolumn{3}{|l|}{ Cardiac complications } \\
\hline No & 66 & $97.1 \%$ \\
\hline Yes & 2 & $2.9 \%$ \\
\hline \multicolumn{3}{|l|}{ Hepatic complications } \\
\hline No & 67 & $98.5 \%$ \\
\hline Yes & 1 & $1.5 \%$ \\
\hline \multicolumn{3}{|l|}{ Spleen complications } \\
\hline No & 68 & $100 \%$ \\
\hline Yes & 0 & $0.0 \%$ \\
\hline \multicolumn{3}{|c|}{ Endocrine system complications } \\
\hline No & 57 & $86.8 \%$ \\
\hline Yes & 11 & $13.2 \%$ \\
\hline \multicolumn{3}{|l|}{ Bone complications } \\
\hline No & 47 & $69.1 \%$ \\
\hline Yes & 21 & $30.9 \%$ \\
\hline
\end{tabular}

As presented in Table 1, a total of 68 patients with TDT were included in this study. Thirty-nine patients (57.4\%) were female, and 29 patients $(42.6 \%)$ were male. The highest proportion of patients $(55.9 \%)$ fell into the $13-18$ years age group. The majority of patients were attending school $(92.7 \%)$. The highest proportion of patients were non-UAE nationals (57.4\%). Approximately 44.1\% of patients had less than 10,000 AED as monthly household income, and $4.4 \%$ of them had no monthly household income. The highest percentage of patients $(30.9 \%)$ were in the second-lowest annual household income quartile, and the lowest percentage of patients $(13.2 \%)$ were in the lowest annual household income quartile.

The major type of disease among patients was BTM (86.8\%). Only one (1.5\%) patient underwent a splenectomy, and more than half of the patients $(57.4 \%)$ had no disease complications. Osteopenia and osteoporosis $(30.9 \%)$ were the main bone complications associated with TDT in pediatric patients, followed by endocrine diseases $(13.2 \%)$, cardiac complications (2.9\%), and liver diseases (1.5\%). DFX was the most common ICT used in TDT patients $(82.4 \%)$, followed by DFO (13.2\%). More than half of patients $(63.2 \%)$ had severely low serum ferritin $(\geq$ $2000 \mathrm{ng} / \mathrm{ml})$, and $36.8 \%$ of patients had mild to moderately low serum ferritin level $(<2000 \mathrm{ng} / \mathrm{ml})$, reflecting inadequate chelation and vulnerability to develop iron overload-related complications.

\subsection{Descriptive Analysis for HRQL in TDT Children Using PedsQL}

The overall QoL for pediatric TDT patients was measured using the PedsQL generic scale. The physical health summary score of the PedsQL includes physical functioning. The psychosocial health summary score includes emotional functioning, social functioning, and school functioning. The median scores for the PedsQL dimensions were illustrated in Figure 1. 


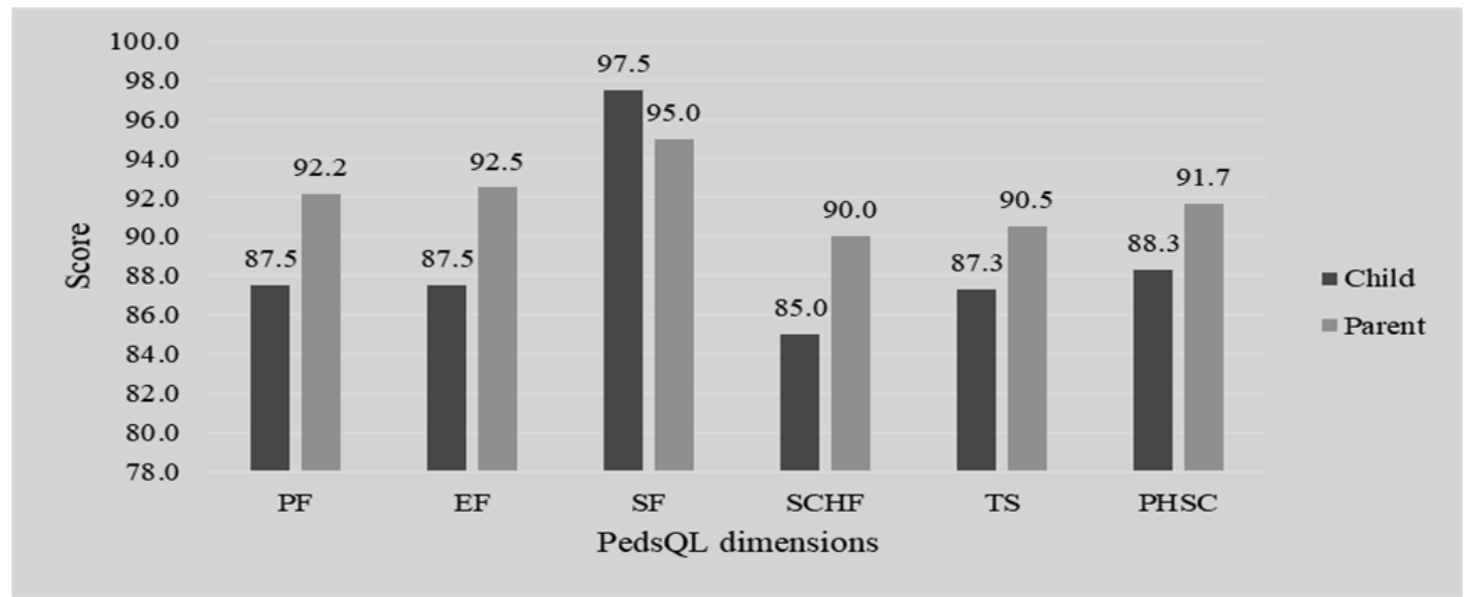

Figure 1. PedsQL dimensions as perceived by TDT children and their parent

Regarding the child self-report, the median total score (TS) was 87.3, and the median score of psychosocial health summary score was 88.3 . The highest median score was in social functioning (97.5), and the lowest median score was in school functioning (85.0).

Regarding the parent-reports, the median total score was 90.5 , and the median score of psychosocial health summary score was 91.7. The highest median score was in social functioning (95.0), and the lowest mean score was in school functioning (90.0) (Table 2).

Table 2. Descriptive analysis of PedsQL score for children with TDT

\begin{tabular}{llccc}
\hline Scale & N & Min. & Max. & Median (IQR) \\
\hline Child self-report & & & & $87.5(10.9)$ \\
Physical functioning & 40 & 56.3 & 100.0 & $87.5(15.0)$ \\
Emotional functioning & 40 & 35.0 & 100.0 & $97.5(10.0)$ \\
Social functioning & 40 & 55.0 & 100.0 & $85.0(18.8)$ \\
School functioning & 40 & 35.0 & 100.0 & $87.3(9.2)$ \\
Total score & 40 & 57.8 & 97.5 & $87.5(10.9)$ \\
Physical functioning score & 40 & 56.3 & 100.0 & $88.3(6.3)$ \\
Psychosocial health summary score & 40 & 58.3 & 98.3 & $92.2(20.3)$ \\
\hline Parent proxy-report & & & & $92.5(18.8)$ \\
Physical functioning & 28 & 34.4 & 100.0 & $95.0(10.0)$ \\
Emotional functioning & 28 & 55.0 & 100.0 & $90.0(23.8)$ \\
Social functioning & 28 & 60.0 & 100.0 & $90.5(15.0)$ \\
School functioning & 28 & 50.0 & 100.0 & $92.2(20.3)$ \\
Total score & 28 & 61.4 & 100.0 & $91.7(11.3)$ \\
Physical functioning score & 28 & 34.4 & 100.0 & 100.0 \\
Psychosocial health summary score & 28 & 60.0 & & \\
\hline
\end{tabular}

\subsection{Relationship between Demographic and Clinical Characteristics of children with TDT and PedsQL Outcomes}

Perceived PedsQL scores were compared from both child's and parent's perspectives for the pediatric TDT patients. No differences were found between the child and parent reports (all $p$ values $>0.05$ ) Table (3). 
Table 3. Differences in child and parent PedsQL scores, expressed as median values

\begin{tabular}{lllll}
\hline Scale & Child & Parent & Difference & $P$-value* \\
\hline Physical functioning & 87.5 & 92.2 & 1.6 & 0.352 \\
Emotional functioning & 87.5 & 92.5 & 0.00 & 0.887 \\
Social functioning & 97.5 & 95.0 & 2.5 & 0.077 \\
School functioning & 85.0 & 90.0 & 0.0 & 0.870 \\
Total score & 87.3 & 90.5 & 0.0 & 0.516 \\
Psychosocial health summary score & 88.3 & 91.7 & 0.0 & 0.845
\end{tabular}

*Wilcoxon signed ranks test.

The total QoL score and the psychosocial health summary score were significantly affected by patients' age, monthly household income, and disease complications. The median total score (96.1) and psychological health summary score (96.7) were significantly higher in patients aged 2-4 years as compared to that of other age groups 90.5 and 90.8 for patients aged 5-7 years, 84.8 and 86.7 for patients aged $8-12$ years, and 87.3 and 88.3 for patients aged 13-18 years, respectively ( $p=0.019$ and 0.025 , respectively). Patients with the highest monthly household income had a statistically significant higher total score (95.2) and psychosocial health summary score (96.7) compared to other monthly household income groups $(p=0.011$ and 0.010 , respectively). Patients with complications had a significantly lower median total score and median psychosocial summary health score $(87.2$ and 88.3 , respectively) than patients without complications $(p=0.037$ and $p=0.022)$. The median physical functioning score (100) was significantly higher in patients aged 2-4 years old as compared to that of other age groups $(p=0.028$ ) (96.9 for patients aged 5-7 years, 89.1 for patients aged 8-12 years, and 87.5 for patients aged 13-18 years). Patients with the highest monthly household income had a statistically significant higher emotional functioning score (95.0) and school functioning score (95.0) compared to other income groups ( $p=0.043$ and 0.018 , respectively). The median school functioning score was significantly higher in patients with complications (90.0) compared to patients without complications $(80.0, p=0.006)$ (Table 4). 
Table 4. PedsQL scores among TDT children's demographic and clinical characteristics $(\mathrm{N}=68)$

\begin{tabular}{|c|c|c|c|c|c|c|c|c|c|c|c|c|}
\hline \multirow[b]{2}{*}{ Item } & \multicolumn{2}{|c|}{ Physical functioning } & \multicolumn{2}{|c|}{ Emotional Functioning } & \multicolumn{2}{|c|}{ Social Functioning } & \multicolumn{2}{|c|}{ School Functioning } & \multicolumn{2}{|l|}{ Total score } & \multicolumn{2}{|l|}{ PSHS score } \\
\hline & $\begin{array}{l}\text { Median } \\
\text { (IQR) }\end{array}$ & $p$-value & $\begin{array}{l}\text { Median } \\
(\mathrm{IQR})\end{array}$ & $p$-value & $\begin{array}{l}\text { Median } \\
\text { (IQR) }\end{array}$ & $p$-value & $\begin{array}{l}\text { Median } \\
\text { (IQR) }\end{array}$ & $p$-value & $\begin{array}{l}\text { Median } \\
\text { (IQR) }\end{array}$ & $p$-value & $\begin{array}{l}\text { Median } \\
\text { (IQR) }\end{array}$ & $p$-value \\
\hline \multicolumn{13}{|l|}{ Age group (years) } \\
\hline $2-4(N=8)$ & $100(11.7)$ & \multirow{4}{*}{0.028} & $95.0(13.8)$ & \multirow{4}{*}{0.076} & $95.0(7.5)$ & \multirow{4}{*}{0.895} & $100(18.8)$ & \multirow{4}{*}{0.092} & $96.1(7.5)$ & \multirow{4}{*}{0.019} & $96.7(8.12)$ & \multirow{4}{*}{0.025} \\
\hline $5-7(\mathrm{~N}=8)$ & $96.9(17.2)$ & & $95.0(18.8)$ & & $95.0(5.0)$ & & $95.0(20.0$ & & $90.5(12.1)$ & & $90.8(10.8)$ & \\
\hline $8-12(\mathrm{~N}=13)$ & $89.1(32.0)$ & & $87.5(16.3)$ & & $100(30.0)$ & & $85.0(20.0)$ & & $84.8(19.8)$ & & $86.7(17.9)$ & \\
\hline $13-18(\mathrm{~N}=38)$ & $87.5(12.5)$ & & $85.0(21.3)$ & & $97.5(11.3)$ & & $85.0(20.0)$ & & $87.3(18.3)$ & & $88.3(15.8)$ & \\
\hline \multicolumn{13}{|l|}{ Gender } \\
\hline Male $(\mathrm{N}=29)$ & $87.5(12.5)$ & \multirow[t]{2}{*}{0.745} & $90.0(17.5)$ & \multirow[t]{2}{*}{0.219} & $95.0(10.0)$ & \multirow[t]{2}{*}{0.376} & $85.0(20.0)$ & \multirow[t]{2}{*}{0.612} & $89.8(10.5)$ & \multirow[t]{2}{*}{0.392} & $90.0(10.8)$ & \multirow[t]{2}{*}{0.302} \\
\hline Female $(\mathrm{N}=39)$ & $87.5(25.0)$ & & $90.0(25.0)$ & & $95.0(15.0)$ & & $85.0(20.0)$ & & $87.7(17.5)$ & & $88.3(15.0)$ & \\
\hline \multicolumn{13}{|l|}{ Nationality } \\
\hline UAE $(\mathrm{N}=29)$ & $90.6(18.8)$ & \multirow[t]{2}{*}{0.362} & $90.0(17.5)$ & \multirow[t]{2}{*}{0.698} & $95.0(10.0)$ & \multirow[t]{2}{*}{0.927} & $90.0(25.0)$ & \multirow[t]{2}{*}{0.166} & $90.0(13.8)$ & \multirow[t]{2}{*}{0.396} & $90.0(10.8)$ & 0.364 \\
\hline Non-UAE $(\mathrm{N}=39)$ & $87.5(12.5)$ & & $90.0(20.0)$ & & $95.0(15.0)$ & & $80.0(17.5)$ & & $88.6(13.0)$ & & $88.3(15.0)$ & \\
\hline Household monthly income & & & & & & & & & & & & \\
\hline $0(\mathrm{~N}=3)$ & $84.4(-)$ & & $65.0(-)$ & & $100.0(-)$ & & $62.5(-)$ & & $81.1(-)$ & & $80.0(-)$ & \\
\hline$<5,000(\mathrm{~N}=10)$ & $93.8(7.0)$ & & $92.5(8.8)$ & & $100.0(6.3)$ & & $90.0(21.3)$ & & $92.6(8.4)$ & & $92.5(10.4)$ & \\
\hline $5,000-9,999(\mathrm{~N}=19)$ & $84.4(12.5)$ & 0219 & $80.0(25.0)$ & 0043 & $90.0(30.0)$ & 0.439 & $80.0(30.0)$ & 0018 & $82.3(18.4)$ & 0011 & $81.7(20.0)$ & 0010 \\
\hline $10,000-19,999(\mathrm{~N}=19)$ & $90.6(18.8)$ & 0.219 & $90.0(20.0)$ & 0.043 & $100.0(10.0)$ & 0.459 & $85.0(22.5)$ & 0.010 & $87.2(15.2)$ & 0.011 & $88.3(10.0)$ & 0.010 \\
\hline $20,000-29,999(\mathrm{~N}=7)$ & $87.5(18.8)$ & & $85.0(20.0)$ & & $95.0(10.0)$ & & $90.0(10.0$ & & $90.5(5.9)$ & & $91.7(5.8)$ & \\
\hline $30,000-39,999(\mathrm{~N}=1)$ & - & & - & & - & & - & & - & & - & \\
\hline$\geq 40,000(\mathrm{~N}=7)$ & $96.9(12.5)$ & & $95.0(5.0)$ & & $95.0(10.0)$ & & $95.0(15.0)$ & & $95.2(6.3)$ & & $96.7(8.3)$ & \\
\hline Ferritin level & & & & & & & & & & & & \\
\hline$<2000 \mathrm{ng} / \mathrm{ml}(\mathrm{N}=43)$ & $87.5(17.2)$ & 0.547 & $90.0(17.5)$ & 0.488 & $95.0(12.5)$ & 0.614 & $90.0(27.5)$ & 0.948 & $88.8(14.5)$ & 0.398 & $88.3(16.7)$ & 0.349 \\
\hline$\geq 2000 \mathrm{ng} / \mathrm{ml}(\mathrm{N}=25)$ & $87.5(15.6)$ & & $90.0(20.0)$ & & $95.0(10.0)$ & & $85.0(20.0)$ & & $91.7(12.2)$ & & $91.7(13.3)$ & \\
\hline ICT & & & & & & & & & & & & \\
\hline $\operatorname{DFX}(\mathrm{N}=56)$ & $87.5(14.8)$ & & $90.0(20.0)$ & & $95.0(10.0)$ & & $85.0(20.0)$ & & $88.4(15.9)$ & & $88.3(14.6)$ & \\
\hline $\operatorname{DFP}(\mathrm{N}=1)$ & - & 0.216 & - & 0.596 & - & 0.877 & - & 0.630 & - & 0.453 & - & 0.589 \\
\hline $\mathrm{DFO}(\mathrm{N}=9)$ & $96.9(12.5)$ & & $90.0(12.5)$ & & $95.0(10.0)$ & & $90.0(35.0)$ & & $93.1(13.1)$ & & $95.0(11.7)$ & \\
\hline Combined treatment $(\mathrm{N}=2)$ & $90.6(-)$ & & $90.0(-)$ & & $95.0(-)$ & & $85.0(-)$ & & $90.2(-)$ & & $90.9(-)$ & \\
\hline Presence of complications & & & & & & & & & & & & \\
\hline Yes $(\mathrm{N}=29)$ & $87.5(12.5)$ & 0.392 & $90.0(20.0)$ & 0.244 & $95.0(12.5)$ & 0.974 & $80.0(20.0)$ & 0.006 & $87.2(17.4)$ & 0.037 & $88.3(13.3)$ & 0.022 \\
\hline No $(\mathrm{N}=39)$ & $90.6(15.6)$ & & $90.0(20.0)$ & & $95.0(10.0)$ & & $90.0(20.0)$ & & $90.5(14.3)$ & & $91.7(11.7)$ & \\
\hline
\end{tabular}


The median total score was weakly negatively correlated with the patient's age and $(\rho=-0.289, \mathrm{~N}=68, p<0.017)$ and weakly positively correlated with monthly household income $(\rho=0.256, \mathrm{~N}=68, p<0.035)$. The median physical health summary score was significantly weakly negatively correlated with patients' age $(\rho=-0.269, \mathrm{~N}=$ $68, p=0.026)$. The median psychosocial health summary score was significantly weakly negatively correlated with patients' age $(\rho=-0.276, \mathrm{~N}=68, p=0.023)$, and weakly positively correlated with monthly household income ( $\rho=0.258, \mathrm{~N}=68, p=0.034)$. The median school functioning score was significantly weakly negatively correlated with patients' age $(\rho=-0.322, \mathrm{~N}=68, p=0.009)$, and weakly positively correlated with monthly household income $(\rho=0.318, \mathrm{~N}=64, p=0.010)$ (Table 5).

Table 5. Correlation between PedsQL scores among children's age and monthly household income $(\mathrm{N}=68)$

\begin{tabular}{llllll}
\hline \multirow{2}{*}{ Item } & \multicolumn{2}{l}{ Age } & & \multicolumn{2}{l}{ Monthly household income } \\
\cline { 2 - 3 } \cline { 5 - 6 } \cline { 5 - 6 } & $\boldsymbol{\rho}$-value* & $\boldsymbol{P}$-value & & $\boldsymbol{\rho}$-value & $\boldsymbol{P}$-value \\
\hline Total score & -0.289 & 0.017 & & 0.256 & 0.035 \\
Psychosocial health summary score & -0.276 & 0.023 & & 0.258 & 0.034 \\
Physical functioning & -0.269 & 0.026 & & 0.203 & 0.098 \\
Emotional functioning & -0.216 & 0.076 & & 0.237 & 0.052 \\
Social functioning & 0.140 & 0.254 & & -0.012 & 0.926 \\
School functioning & -0.322 & 0.009 & & 0.318 & 0.010 \\
\hline
\end{tabular}

Note. $\rho$-value $=$ rho value (Spearman's rank-order correlation).

\subsection{Identifying Predictors of the QoL among Children with TDT}

The linear regression model was used to determine the significant predictors of the PedsQL total score (continuous dependent variable). The following independent variables were used in the model: age, monthly household income, and disease complications. All assumptions were checked and adjusted; homoscedasticity, normality of residuals, and multicollinearity were satisfied. For outliers, cases with standard residuals greater than two standard deviations were removed. A stepwise selection method was used to select the predictors.

The following regression equation was constructed according to the linear regression analysis:

Total score $=4.51-0.007\left(\mathrm{x}_{1}\right)$

Where $\mathrm{x}_{1}$ is the patients' age,

The linear regression identified one significantly negative predictor for the total score, the patients' age. The model indicated that $11.1 \%$ of the variance in the total score could be predicted from the independent variable: the children's age $(\mathrm{F}(2,62)=5.26, p=0.003)$ (Table 6).

According to the regression analysis, a one-year increase in TDT children's age was associated with a $0.70 \%$ decrease in a PedsQL total score.

Table 6. Factors associated with the total PedsQL score among children with TDT

\begin{tabular}{llllc}
\hline Parameter & Coef. & Robust S.E. & P-value & $95 \%$ CI \\
\hline Age & -0.007 & 0.003 & 0.003 & $-0.01-(-0.002)$ \\
Monthly income & $1.47 \times 10^{-6}$ & $1.29 \times 10^{-6}$ & 0.259 & $-1.1 \times 10^{-6}-4.05 \times 10^{-6}$ \\
\hline
\end{tabular}

\subsection{Risk Factors for Low HRQoL in Children with TDT}

Patients were stratified into two groups according to the total QoL score, with a cut-off point of 75 (Saha, Misra, \& Saha, 2015), and then the relationship between the total QoL score and potential risk factors was evaluated.

A logistic regression model was used to determine the low HRQoL score predictors (dependent binomial variable). The following independent variable was used in the model: children's age. No multicollinearity was observed, and the Box-Tidwell procedure checked the linearity of logit on SPSS. Mahalanobis' distance test was used to check outliers. 
The following regression equation was constructed according to the logistic regression analysis:

Low total score $=-0.03+1.2\left(\mathrm{x}_{1}\right)$

Where $\mathrm{x}_{1}$ is the disease complications,

The logistic regression identified one statistically significant positive predictor for the low PedsQL total score, the children's age. Logistic regression analysis demonstrated that increasing children's age was associated with a higher risk factor for low PedsQL total score (OR: 1.2, 95\% CI:1.02 - 1.33, $p=0.021$ ) (Table 7).

Table 7. Logistic regression analysis of pediatric TDT patients with a total QoL score $<75$ (low QoL)

\begin{tabular}{lllll}
\hline Parameter & Odds Ratio & Robust S.E. & P-value & $95 \%$ CI \\
\hline Age & 1.2 & 0.08 & 0.021 & $1.02-1.33$ \\
\hline
\end{tabular}

\section{Discussion}

HRQoL is an important healthcare outcome in clinical practice, as well as improving strategies, healthcare services research, and understanding the impact of diseases and treatment on children's HRQoL (Germain et al., 2019; Varni J. W., Burwinkle, \& Lane, 2005). Many studies have been conducted to assess the HRQoL in children with TDT. Knowledge of factors associated with HRQoL among patients with TDT is essential in improving these patients' treatment outcomes (Thavorncharoensap et al., 2010).

The study revealed a concordance between parents and children in terms of the PedsQL rating scale. Similarly, Surapolchai et al. (2010) showed an agreement between parents' and children's reports using the PedsQL generic core scales. A possible explanation may be the strong child-parent relationship and the good parental knowledge concerning children's experiences and health problems.

The QoL in this study showed that school functioning had the lowest score. Several studies in the region reported low school functioning among TDT patients (Ayoub et al., 2013; Gharaibeh \& Gharaibeh, 2011; Mevada et al., 2016; Nashwan et al., 2018). Mevada et al. (2016) assessed the QoL of TDT Omani children and revealed that school functioning scored the lowest. Moreover, Nashwan et al. (2018) assessed the QoL of TDT Qatari patients and reported that TDT patients had lower school performances compared to healthy controls. Ayoub et al. (2013) conducted a cross-sectional study in Saudi Arabia to evaluate TDT patients' QoL and showed that school functioning scored the lowest. Gharaibeh and Gharaibeh (2011) evaluated the QoL of TDT Jordanian patients and showed that the lowest mean scores for thalassemic children were reported for school functioning. This could be explained by 1) the frequent absenteeism from school for blood transfusion and hospital visits and 2) by the fatigue interfering with performance of academic activities, especially in the days before the blood transfusion, which had a significant effect on the children's QoL (Ismail et al., 2006; Musallam, Cappellini, \& Taher, 2008).

Consistent with other studies' findings (Dhirar et al., 2016; Hakeem et al., 2018), older patients tended to report worse overall QoL scores, lower physical function, psychosocial health summary scores, and worse school functioning scores. This study found that adolescent patients had a significantly lower QoL than younger counterparts. One explanation for the relationship between age and QoL score is that younger age is associated with less iron overload and fewer complications, more physical activity, and more emotional stability. Moreover, as the patients grow, they experience repeated blood transfusion visits and more missed school. These factors could result in poor self-esteem, expression of negative thoughts about their lives, and feelings of hurt toward their chronic disease (Eldakhakhny, 2011).

Higher monthly income was associated with a higher overall QoL score, better emotional functioning, higher psychosocial health summary score, and higher school functioning. Similar to our finding, many studies suggest that socioeconomic level is associated with QoL (Clarke et al., 2010; Hakeem et al., 2018; Sharma et al., 2017). This could be explained by the fact that the low economic level of families can add more burden to these patients as their parents cannot provide a comfortable life suitable for the special needs of these children, which leads to difficulty in coping with the disease and worse emotional functioning, and hence lower school functioning.

Previous studies have shown a significant difference in the QoL scores among boys and girls (Bazi et al., 2017; Dhirar et al., 2016; Jameel \& Im, 2015; Negin Hadi, Donya Karami, \& Ali Montazeri, 2009). Dhirar et al. (2016) reported a significantly higher HRQoL score in boys' emotional domain than in girls, but the total score was not significantly different between them. Jameel and $\operatorname{Im}$ (2015) reported that female patients secured low scores compared to male patients in almost all QoL scores. Negin Hadi et al. (2009) revealed that female patients had 
higher scores than male patients in social functioning. Bazi et al. (2017) revealed that female patients had lower QoL scores compared to male patients. In our study, sex was not associated with the QoL of TDT patients. Similar to our result, Thavorncharoensap et al. (2010) evaluated the HRQoL and recorded no significant difference in total HRQoL score between boys and girls. Abdul-Zahra, Hassan, and Ahmed (2016) evaluated the HRQoL in Iraqi TDT children and reported no significant difference between boys and girls in QoL scores. Jafari-Shakib, Davoudi- Kiakalaye, Pour-Fathollah, et al. (2016) reported that no association was found between boys and girls in QoL scores. This could be explained by the fact that major problems between boys and girls are common in TDT children.

In our study, we found that TDT patients with complications had a significantly lower median of PedsQL total score, psychosocial health summary score, and school functioning. This finding is in line with other studies (Gharaibeh \& Gharaibeh, 2011; Thavorncharoensap et al., 2010; Tuysuz \& Tayfun, 2017). Gharaibeh and Gharaibeh (2011) reported that complications were associated with lower PedsQL, and Tuysuz and Tayfun (2017) showed that the presence of complications negatively affected the QoL. Moreover, Thavorncharoensap et al. (2010) suggested that complications were associated with the low overall QoL score. This could be explained by the fact that complications associated with repeated blood transfusion, such as bone problems (osteopenia and osteoporosis) and endocrine problems (lack of secondary sexual characters of young boys and girls), could limit the physical function of TDT patients and lead to isolations and depression and the development of a psychiatric mindset. Moreover, patients with complications had more frequent hospital visits and transfusions, which lead to missed school days due to ill health and frequent hospitalizations.

Although existing evidence indicates that iron overload could result in severe morbidity and mortality (Borgna-Pignatti et al., 2004; Olivieri et al., 1994), the severe serum ferritin $(\geq 2,000 \mathrm{ng} / \mathrm{ml})$ is associated with cardiac problems and mortality (Borgna-Pignatti et al., 2004). Furthermore, the previous study of (Salama et al., 2014) reported an association between higher ferritin level and lower total QoL score; no differences were found in our study in PedsQL scores among different iron chelators and ferritin levels. Similar to our finding, Jafari-Shakib et al. (2016) found no significant differences between the PedsQL scores and serum ferritin levels. This contradictory result could be explained by the fact that long-term iron-overload occurs gradually, and elevated serum ferritin level could not show any visible symptoms, and hence no effect on patients' QoL.

Regression analyses were conducted in TDT pediatric patients and revealed that age was a negative predictor for the QoL total score, and increasing age was associated with a higher risk for a low PedsQL total score. Similar to other studies (Dhirar et al., 2016; Hakeem et al., 2018; Sobota et al., 2011), age was a significant predictor for QoL score. This could be explained by the fact that older age increases the probability of iron overload and complications that negatively affect TDT patients' QoL.

This study has several limitations that are mainly related to research design, and availability of data extracted from the patients' medical records. First, this study follows a cross-sectional descriptive study design, and the best way to evaluate the QoL of patients is through longitudinal study design and recruitment of a healthy control group, where patients are followed up throughout their disease via serial assessments, identify the casual association among the predictors for the HRQoL, and confirm the findings. Second, the availability of some variables could be potential predictors for the QoL of TDT. For example, the age at onset of anemia is not available in the patients' medical records. Also, pre-transfusion $\mathrm{Hb}$ level did not extract from the patients' medical records. Furthermore, the HRQoL scores of healthy people in the UAE are not available. So, it is difficult to estimate the true magnitude of thalassemia's impact on patients' QoL. Third, there is no consensus on how to differentiate the severity of thalassemia disease, thus different criteria to evaluate thalassemia's severity in different studies were found (Phadke \& Agarwal, 2003; Sripichai et al., 2008), which could affect the quality of comparison between studies. Finally, there was a concern for selection bias as it only included thalassemia patients from a single center. However, since the Dubai Thalassemia Center has the largest number of thalassemia patients in Dubai and covers about half of the thalassemia patients in the UAE, we believe that were representative of the thalassemia population in Dubai.

\section{Conclusion}

Overall, the finding of this study revealed that age is a significant predictor of a poor QoL. Therefore, children with TDT and their families require long-term support for the prevention of physical and mental problems associated with TDT. Moreover, the thalassemia center should reorganize its schedules for blood transfusions on weekends or in the evening, to enable school children to overcome the low school performance. In addition, psychosocial intervention related to school functioning, such as assistance with schoolwork should be implemented to improve the HRQoL in TDT children. 


\section{Acknowledgments}

The present study is grateful to Dubai Thalassemia Center for their assistance in this study, as well as all patients and their parents who participated in this study.

\section{Competing Interests Statement}

The authors declare that there are no competing or potential conflicts of interest.

\section{References}

Abdul-Zahra, H. A., Hassan, M. K., \& Ahmed, B. A. (2016). Health-Related Quality of Life in Children and Adolescents with Beta-Thalassemia Major on Different Iron Chelators in Basra, Iraq. $J$ Pediatr Hematol Oncol, 38(7), 503-511. https://doi.org/10.1097/MPH.0000000000000663

Arabiat, D., Elliott, B., Draper, P., \& Al Jabery, M. (2011). Cross-Cultural Validation of the Pediatric Quality of Life Inventory ${ }^{\mathrm{TM}} 4.0$ (Pedsql ${ }^{\mathrm{TM}}$ ) Generic Core Scale into Arabic Language. Scand J Caring Sci, 25(4), 828-833. https://doi.org/10.1111/j.1471-6712.2011.00889.x

Ayoub, M. D., Radi, S. A., Azab, A. M., Abulaban, A. A., Balkhoyor, A. H., Seif-Eleslam, W. B., .. Kari, J. A. (2013). Quality of Life among Children with Beta-Thalassemia Major Treated in Western Saudi Arabia. Saudi medical journal, 34(12), 1281-1286.

Bayanzay, K., \& Alzoebie, L. (2016). Reducing the Iron Burden and Improving Survival in Transfusion-Dependent Thalassemia Patients: Current Perspectives. Journal of blood medicine, 7, 159-169. https://doi.org/10.2147/JBM.S61540

Bazi, A., Sargazi-Aval, O., Safa, A., \& Miri-Moghaddam, E. (2017). Health-Related Quality of Life and Associated Factors among Thalassemia Major Patients, Southeast of Iran. J Pediatr Hematol Oncol, 39(7), 513-517. https://doi.org/10.1097/MPH.0000000000000963

Borgna-Pignatti, C. (2010). The Life of Patients with Thalassemia Major. Haematologica, 95(3), 345-348. https://doi.org/10.3324/haematol.2009.017228

Borgna-Pignatti, C., Rugolotto, S., De Stefano, P., Zhao, H., Cappellini, M. D., Del Vecchio, G. C., . . Cnaan, A. (2004). Survival and Complications in Patients with Thalassemia Major Treated with Transfusion and Deferoxamine. Haematologica, 89(10), 1187-1193.

Bullinger, M. (2002). Assessing Health Related Quality of Life in Medicine. An Overview over Concepts, Methods and Applications in International Research. Restorative Neurology And Neuroscience, 20(3-4), 93-101.

Clarke, S., Skinner, R., Guest, J., Darbyshire, P., Cooper, J., Shah, F., . . Eiser, C. (2010). Health-Related Quality of Life and Financial Impact of Caring for a Child with Thalassaemia Major in the Uk. Child: care, health and development, 36(1), 118-122. https://doi.org/10.1111/j.1365-2214.2009.01043.x

Cunningham, M. J., Macklin, E. A., Neufeld, E. J., Cohen, A. R., \& Network, T. C. R. (2004). Complications of B-Thalassemia Major in North America. Blood, 104(1), 34-39. https://doi.org/10.1182/blood-2003-09-3167

Dhanya, R., Sedai, A., Ankita, K., Parmar, L., Agarwal, R. K., Hegde, S., . . Faulkner, L. (2020). Life Expectancy and Risk Factors for Early Death in Patients with Severe Thalassemia Syndromes in South India. Blood advances, 4(7), 1448-1457. https://doi.org/10.1182/bloodadvances.2019000760

Dhirar, N., Khandekar, J., Bachani, D., \& Mahto, D. (2016). Thalassemia Major: How Do We Improve Quality of Life? SpringerPlus, 5(1), 1895. https://doi.org/10.1186/s40064-016-3568-4

Elalfy, M., Farid, M., Labib, J., \& Rezkallah, H. (2014). Quality of Life of Egyptian B-Thalassemia Major Children and Adolescents. The Egyptian Journal of Haematology, 39(4), 222-226. https://doi.org/10.4103/1110-1067.153963

El-Dakhakhny, A. (2011). Quality of Life of School Age Thalassemic Children at Zagazig City. The Journal of American Science.

Eldakhakhny, A. M. M. (2011). Quality of Life of School Age Thalassemic Children at Zagazig City. Journal of American Science.

Emadi Dehaghi, B., Rasooli, L., \& Mohammadi Farsani, S. (2016). Quality of Life among Patients with Beta-Thalassemia Major in Shahrekord City, Iran. International Journal of Epidemiologic Research, 3(4), 324-328. 
Feeny, D. H., Eckstrom, E., Whitlock, E. P., \& Perdue, L. A. (2013). A Primer for Systematic Reviewers on the Measurement of Functional Status and Health-Related Quality of Life in Older Adults.

Galanello, R., \& Origa, R. (2010). Beta-Thalassemia. Orphanet journal of rare diseases, 5, 11-11. https://doi.org/10.1186/1750-1172-5-11

Germain, N., Aballéa, S., \& Toumi, M. (2019). Measuring the Health-Related Quality of Life in Young Children: How Far Have We Come? Journal of market access \& health policy, 7(1), 1618661-1618661. https://doi.org/10.1080/20016689.2019.1618661

Gharaibeh, H., \& Gharaibeh, M. (2011). Factors Influencing Health-Related Quality of Life of Thalassaemic Jordanian Children. Child: care, health and development, 38, 211-218. https://doi.org/10.1111/j.1365-2214.2011.01224.x

Gollo, G., Savioli, G., Balocco, M., Venturino, C., Boeri, E., Costantini, M., \& Forni, G. L. (2013). Changes in the Quality of Life of People with Thalassemia Major between 2001 and 2009. Patient preference and adherence, 7, 231-236. https://doi.org/10.2147/PPA.S42133

Hachim, I. Y., Nuaimi, Y. E. A., \& Baky, A. a. E. (2014). Quality of Life in Patients Suffering from Thalassaemia in Ras Al Khaimah, United Arab Emirates. Hamdan Medical Journal, 7(1), 1-7. Sheikh Hamdan Bin Rashid Al Maktoum Award for Medical Sciences. https://doi.org/10.7707/hmj.v7i1.290

Hadi, N., Karami, D., \& Montazeri, A. (2009). Health-Related Quality of Life in Major Thalassemic Patients. Quarterly Journal Payesh, 8, 387-393.

Hakeem, G. L. A., Mousa, S. O., Moustafa, A. N., Mahgoob, M. H., \& Hassan, E. E. (2018). Health-Related Quality of Life in Pediatric and Adolescent Patients with Transfusion-Dependent Ss-Thalassemia in Upper Egypt (Single Center Study). Health Qual Life Outcomes, 16(1), 59. https://doi.org/10.1186/s12955-018-0893-z

Ismail, A., Campbell, M. J., Ibrahim, H. M., \& Jones, G. L. (2006). Health Related Quality of Life in Malaysian Children with Thalassaemia. Health Qual Life Outcomes, 4, 39. https://doi.org/10.1186/1477-7525-4-39

Jafari-Shakib, A., Davoudi- Kiakalaye, A., Pour-Fathollah, A., Jafari-Shakib, R., \& Mohtasham-Amiri, Z. (2016). Health-Related Quality of Life in B Thalassemia Major Children in North of Iran. Iranian Journal of Blood and Cancer, 8(4), 108-111.

Jameel, T., \& Im, S. (2015). The Compromised Quality of Life in B-Thalassemia Major Children in Non- Urban Setup in a Developing Country (Vol. 4). https://doi.org/10.4172/2329-8790.1000245

Mahmoud, M. a. M. (2015). Health Related Quality of Life in Thalassemia Patients Treated by Iron Chelation Therapy in the United Arab Emirates.

Mevada, S. T., Al Saadoon, M., Zachariah, M., Al Rawas, A. H., \& Wali, Y. (2016). Impact of Burden of Thalassemia Major on Health-Related Quality of Life in Omani Children. J Pediatr Hematol Oncol, 38(5), 384-388. https://doi.org/10.1097/MPH.0000000000000565

Mueller, P. S., Plevak, D. J., \& Rummans, T. A. (2001). Religious Involvement, Spirituality, and Medicine: Implications for Clinical Practice. Paper presented at the Mayo clinic proceedings. https://doi.org/10.4065/76.12.1225

Musallam, K., Cappellini, M. D., \& Taher, A. (2008). Challenges Associated with Prolonged Survival of Patients with Thalassemia: Transitioning from Childhood to Adulthood. Pediatrics, 121(5), e1426-e1429. https://doi.org/10.1542/peds.2007-1944

Nashwan, A. J., Yassin, M. A., Babu, G. D. J., Nair, S. L. K., Libo-On, I. L., Hijazi, H. A., . . Soliman, A. (2018). Quality of Life among Adolescents Aged 14 to 18 Years with Beta-Thalassemia Major (Tm) in Qatar. Acta Biomed, 89(2-s), 16-26. https://doi.org/10.23750/abm.v89i2-S.7083

Negin Hadi, Donya Karami, \& Ali Montazeri. (2009). Health-Related Quality of Life in Major Thalassemic Patients. Health Monitor Journal of the Iranian Institute for Health Sciences Research, 8(4), 387-393.

Olivieri, N. F., Nathan, D. G., Macmillan, J. H., Wayne, A. S., Liu, P. P., Mcgee, A., . . Cohen, A. R. (1994). Survival in Medically Treated Patients with Homozygous Beta-Thalassemia. N Engl J Med, 331(9), 574-578. https://doi.org/10.1056/NEJM199409013310903

Phadke, S. R., \& Agarwal, S. (2003). Phenotype Score to Grade the Severity of Thalassemia Intermedia. Indian J Pediatr, 70(6), 477-481. https://doi.org/10.1007/BF02723137 
Saha, R., Misra, R., \& Saha, I. (2015). Health Related Quality of Life and Its Predictors among Bengali Thalassemic Children Admitted to a Tertiary Care Hospital. Indian J Pediatr, 82(10), 909-916. https://doi.org/10.1007/s12098-014-1670-6

Salama, H., Hussein, H., Al Faisal, W., Belhool, K., El Sawaf, E., \& Wasfy, A. (2014). Health Related Quality of Life in Transfusion-Dependent Thalassemia Major Patients and Associated Factors in Dubai, Uae, 2011. Middle East J Fam Med, 7(10).

Shafie, A. A., Chhabra, I. K., Wong, J. H. Y., Mohammed, N. S., Ibrahim, H. M., \& Alias, H. (2020). Health-Related Quality of Life among Children with Transfusion-Dependent Thalassemia: A Cross-Sectional Study in Malaysia. Health and Quality of Life Outcomes, 18(1), 141. https://doi.org/10.1186/s12955-020-01381-5

Sharma, S., Seth, B., Jawade, P., Ingale, M., \& Setia, M. S. (2017). Quality of Life in Children with Thalassemia and Their Caregivers in India. The Indian Journal of Pediatrics, 84(3), 188-194. https://doi.org/10.1007/s12098-016-2267-z

Sobota, A., Yamashita, R., Xu, Y., Trachtenberg, F., Kohlbry, P., Kleinert, D. A., . . Neufeld, E. J. (2011). Quality of Life in Thalassemia: A Comparison of Sf-36 Results from the Thalassemia Longitudinal Cohort to Reported Literature and the Us Norms. Am J Hematol, 86(1), 92-95. https://doi.org/10.1002/ajh.21896

Sripichai, O., Makarasara, W., Munkongdee, T., Kumkhaek, C., Nuchprayoon, I., Chuansumrit, A., . . Fucharoen, S. (2008). A Scoring System for the Classification of Beta-Thalassemia/Hb E Disease Severity. Am J Hematol, 83(6), 482-484. https://doi.org/10.1002/ajh.21130

Surapolchai, P., Satayasai, W., Sinlapamongkolkul, P., \& Udomsubpayakul, U. (2010). Biopsychosocial Predictors of Health-Related Quality of Life in Children with Thalassemia in Thammasat University Hospital. $J$ Med Assoc Thai, 93(Suppl 7), 65-75.

Telfer, P., Constantinidou, G., Andreou, P., Christou, S., Modell, B., \& Angastiniotis, M. (2005). Quality of Life in Thalassemia. Annals of the New York Academy of Sciences, 1054(1), 273-282. https://doi.org/10.1196/annals.1345.035

Thavorncharoensap, M., Torcharus, K., Nuchprayoon, I., Riewpaiboon, A., Indaratna, K., \& Ubol, B.-O. (2010). Factors Affecting Health-Related Quality of Life in Thai Children with Thalassemia. BMC blood disorders, 10, 1-1. https://doi.org/10.1186/1471-2326-10-1

Tuysuz, G., \& Tayfun, F. (2017). Health-Related Quality of Life and Its Predictors among Transfusion-Dependent

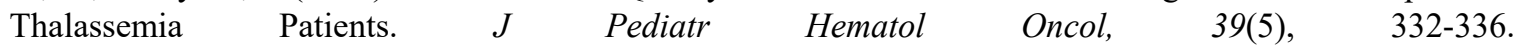
https://doi.org/10.1097/MPH.0000000000000790

Varni, J. W., Burwinkle, T. M., \& Lane, M. M. (2005). Health-Related Quality of Life Measurement in Pediatric Clinical Practice: An Appraisal and Precept for Future Research and Application. Health and Quality of Life Outcomes, 3, 34-34. https://doi.org/10.1186/1477-7525-3-34

Varni, J. W., Seid, M., \& Kurtin, P. S. (2001). Pedsql 4.0: Reliability and Validity of the Pediatric Quality of Life Inventory Version 4.0 Generic Core Scales in Healthy and Patient Populations. Med Care, 39(8), 800-812. https://doi.org/10.1097/00005650-200108000-00006

Vitrano, A., Calvaruso, G., Lai, E., Colletta, G., Quota, A., Gerardi, C., . . . Maggio, A. (2017). The Era of Comparable Life Expectancy between Thalassaemia Major and Intermedia: Is It Time to Revisit the Major-Intermedia Dichotomy? British Journal of Haematology, 176(1), 124-130. https://doi.org/10.1111/bjh.14381

Watson, J. (2001). How to Determine a Sample Size: Tipsheet\# 60. University Park, PA: Penn State Cooperative Extension, 1-5.

\section{Copyrights}

Copyright for this article is retained by the author(s), with first publication rights granted to the journal.

This is an open-access article distributed under the terms and conditions of the Creative Commons Attribution license (http://creativecommons.org/licenses/by/4.0/). 